\title{
Human and nonhuman bioethics
}

\author{
Michael J. Selgelid $^{1} \cdot$ Justin Oakley $^{1}$
}

In July 2016 the Monash University Centre for Human Bioethics changed its name to the Monash Bioethics Centre. When the Centre was first established in 1980, cofounders Peter Singer and Helga Kuhse were asked to name it in terms of human bioethics in particular - and this was apparently motivated by the aim to distance the work of the Centre from co-founder Peter Singer's more general work in animal ethics.

Our decision to change the Centre's name was partly motivated by recognition (in light of comments from colleagues) that its previous name gave the impression that its work was limited to a subset of bioethical issues-i.e., those pertaining to humans in particular. This was unfortunate because, like many other bioethics centres around the world, our Centre's work concerns bioethics broadly conceived. Some prototypical topics in bioethics (e.g., pertaining to animal research and/or creation of new life forms), including areas of our own teaching and research, are not essentially human-oriented. Recent developments in the field, furthermore, have included increased coverage of environmental (as opposed to primarily human) matters - as illustrated, among other things, by appeal to the One Health movement in public health ethics (which we consider a subdiscipline of bioethics).

Though this journal was never named Monash Human Bioethics Review, we are happy to explicitly confirm that we welcome submission of papers concerned with traditional, contemporary, and emerging topics in bioethics generally speaking: i.e., human and nonhuman-including transhuman and posthuman-bioethics.

Michael J. Selgelid

michael.selgelid@monash.edu

1 Monash University, Clayton, Australia 